\title{
AVALIAÇÃO DA PREFERÊNCIA PAISAGÍSTICA NO JARDIM BOTÂNICO DE CURITIBA, PARANÁ, BRASIL
}

\author{
Raquel Ribeiro de Souza Silva ${ }^{12}$, Daniela Biondi ${ }^{3}$
}

\section{RESUMO}

A análise das preferências paisagísticas dos indivíduos constitui-se em uma importante ferramenta para avaliação e aprimoramento da experiência turística. O objetivo desta pesquisa foi realizar uma avaliação paisagística no atrativo mais visitado da cidade de Curitiba, o Jardim Botânico, através dos cartões postais que retratam sua imagem, considerando a percepção de seus usuários em relação à paisagem dos cartões postais, para assim agregar dados qualitativos sobre o uso deste atrativo e fornecer subsídios a sua gestão. O método utilizado foi análise da tipologia e da composição paisagística dos dez cartões postais com a temática "Jardim Botânico de Curitiba”, por meio da desagregação da paisagem e quantificação dos elementos previamente definidos como naturais, antrópicos e culturais. Em seguida, selecionaram-se aqueles que obtiveram a maior porcentagem de elementos naturais, antrópicos e culturais em sua composição para serem apresentados aos usuários que responderiam ao questionário e assim analisar a preferência paisagística destes em relação ao atrativo em estudo. Os resultados encontrados quanto à paisagem retratada nos cartões postais, o que apresentou a maior quantidade de elementos culturais foi o que mais agradou aos usuários. Ao se considerar os fatores gênero, faixa etária, escolaridade e origem geográfica do entrevistado encontraram-se variações na preferência paisagística.

Palavras-chaves: Paisagem; Turismo; Percepção.

\section{ASSESSMENT OF LANDSCAPE PREFERENCE IN THE BOTANICAL GARDEN OF CURITIBA, PARANÁ, BRAZIL}

\begin{abstract}
The analysis of landscape preferences of individuals constitutes an important tool for evaluating and improving the tourist experience. The objective of this research was to make an assessment in landscape at the most visited attraction in the city of Curitiba, the Botanical Garden, through the postcards which portray your image, considering the perception of their users in relation to the landscape of the postcards, in order to add qualitative data on the use of this attractive and provide subsidies to their management. The method uses was analysis of the typology and landscape composition of ten postcards with the theme "Botanical Garden of Curitiba" by the breakdown of the landscape and quantification of elements previously defined as natural, cultural and man-made. Then, were selected those who had the highest percentage of natural elements, man-made and cultural in its composition to be presents to users who respond to the questionnaire and thus examine the landscape preference in relation to the appeal under consideration. The findings about the landscape depicted on postcards, showed that the largest amount of cultural elements was the most pleased to users. When considering the factors as gender, age, education level and geographic origin of the respondent there were variations in landscape preference.
\end{abstract}

Keywords: Landscape; Tourism; Perception.

\footnotetext{
${ }^{1}$ Bacharel em Turismo pela Universidade Estadual Paulista Júlio de Mesquita Filho. Mestre em Engenharia Florestal pela Universidade Federal do Paraná. Curitiba. Paraná. E-mail: unesp2004@yahoo.com.br.

${ }^{2}$ recebido em 30.05.2012 e aceito para publicação em 15.03.2013

${ }^{3}$ Eng. Florestal. Prof ${ }^{\mathrm{a}}$. Dr ${ }^{\mathrm{a}}$ Depto. de Ciências Florestais - Universidade Federal do Paraná. Curitiba. Paraná. E-mail: dbiondi@ufpr.br
} 
Atualmente, o termo paisagem possui inúmeras definições, as quais diferem-se entre si apenas na abordagem em consonância com a formação acadêmica, experiência e linha de estudo do pesquisador.

Dentre as inúmeras definições, considerar-se-á neste estudo, a definição de Biondi (1990), que afirma ser a paisagem "um conjunto de cenários naturais ou artificiais onde o homem é, alem de observador, um de uma gama de elementos que compõem qualquer panorama”.

Desta forma observa-se que em relação á atividade turística é nos usos que se concentram os significados mais profundos da paisagem e que a relação entre turismo e paisagem é marcada pela contraditoriedade, podendo produzir tanto efeitos positivos quanto negativos ao ambiente e a comunidade receptiva (MENESES, 2004).

Cruz (2002) complementa a discussão sobre a relação turismo e paisagem, afirmando que no turismo, a paisagem é a primeira instância do contato do indivíduo com o lugar visitado estando , por esta razão, no centro da atratividade dos lugares para o turismo.

Estando no centro da atratividade, as paisagens podem ser consideradas testemunhos visuais de elementos estéticos e simbólicos construídos historicamente (SILVA, 2004). Ao serem identificados e apropriados pelos indivíduos, estes elementos, despertam singular interesse pelo lugar visitado e contribuem para estabelecer uma valorização qualitativa.

Neste contexto, onde a paisagem é um elemento essencial na oferta turística, a composição e harmonia das formas e cores não passam despercebidas (SILVA, 2004), a análise das preferências paisagísticas dos indivíduos constitui-se em uma ferramenta para avaliação e aprimoramento da qualidade dos atrativos turísticos.

Algumas características da paisagem são responsáveis pela preferência ou rejeição do observador. Estas características podem ser concretas ou abstratas. Gonzáles Bernáldes (1981) apud Bolós (1992) faz uma compilação de diversos autores e assinala como concretude na paisagem a presença de água, vegetação e minerais, enquanto que o aspecto abstrato é definido pela perspectiva, complexidade, coerência, mistério, diversidade e a variedade contida na paisagem.

A combinação de alguns destes elementos torna uma paisagem atrativa ao observador, por outro lado a ausência deles pode ocasionar um desinteresse do observador frente à determinada paisagem.

Assim, no momento de analisar a preferência por paisagens, uma ferramenta útil é o conhecimento do tipo de paisagem que está sendo observada, pois esta informação fornece subsídios ao entendimento e discussão sobre as razões que tornam uma paisagem agradável ou desagradável ao olhar do observador.

Biondi (1990) concede as seguintes tipologias à paisagem: panorâmica, fechada, focada, centralizada, limitada, detalhe e temporária.

A paisagem panorâmica é aquela onde predominam os elementos horizontais, a imagem fica em primeiro plano e não há limites para a visão. Enquanto que a paisagem focada conta com linhas paralelas ou objetos alinhados que parecem convergir ate um ponto focal que domina a cena. 
Uma paisagem fechada é definida pela presença de barreiras visuais. Igualmente a paisagem classificada como limitada tem seu espaço envolvido por barreiras visuais ou espaços cercados ou fechados.

Centralizada é aquela paisagem dominada pela presença de um componente singular que centra a atenção do observador. Diferente da paisagem detalhe ou temporária, que proporciona uma observação temporária de um elemento da paisagem e produz um impacto incomum por influencia de elementos instáveis da natureza.

Bolós (1992) classifica as paisagens quanto às características geográficas e a dominância de elementos, podendo ser distinguidas como naturais, artificiais ou antrópicas.
Observa-se, portanto, a existência de um leque variado de opções no sentido de classificar paisagens, igualmente diverso são os métodos de avaliação destas. A escolha entre uma ou outra classificação, bem como um ou outro método dependerá exclusivamente dos objetivos propostos pelo pesquisador. O objetivo desta pesquisa foi então realizar uma avaliação paisagística no atrativo mais visitado da cidade de Curitiba, o Jardim Botânico, através dos cartões postais que retratam sua imagem, considerando a percepção de seus usuários em relação à paisagem dos cartões postais e da área de estudo, para assim agregar dados qualitativos sobre o uso deste atrativo e fornecer subsídios a sua gestão paisagística.

\section{MATERIAL E MÉTODOS}

O objeto de estudo, Jardim Botânico, localiza-se na cidade de Curitiba, capital do Estado do Paraná, no bairro Jardim Botânico, entre a Avenida Lothário Meissner e a Rua Ostoja Roguski, conforme ilustra a figura 1. O atrativo dispõe de uma área de 17,8 ha, a qual está situada nas coordenadas geográficas: $25^{\circ} 26^{\prime} \mathrm{S}$ e 491'' (RBJB, 2004).

O Jardim Botânico de Curitiba foi inaugurado em cinco de outubro de 1991 e proporciona diversas atividades em seu espaço, tanto para os moradores da cidade de Curitiba, como para os indivíduos que a visitam. A nomenclatura oficial é uma homenagem à urbanista Francisca Maria Garfunkel Rischbieter, pioneira no trabalho de planejamento urbano da capital paranaense (IPPUC, 2007).

O local funciona como centro de pesquisas da flora do Estado do Paraná, além de contribuir com a preservação e conservação da natureza, por meio de atividades desenvolvidas no centro de educação ambiental e no jardim das sensações.

Além dos aspectos ambientais e educacionais, o Jardim Botânico de Curitiba possui também significativa importância como atrativo turístico, o qual possui acesso por meio dos ônibus: Expresso Centenário, Capão da Imbuia ou da Linha Turismo.

Segundo dados da Secretaria de Estado do Turismo, em Curitiba, no ano de 2007, o Jardim Botânico de Curitiba, posicionou-se em primeiro lugar no ranking dos atrativos mais citados pelos entrevistados daquele ano (IPPUC, 2007). 
Figura 1 - Localização do Jardim Botânico de Curitiba.

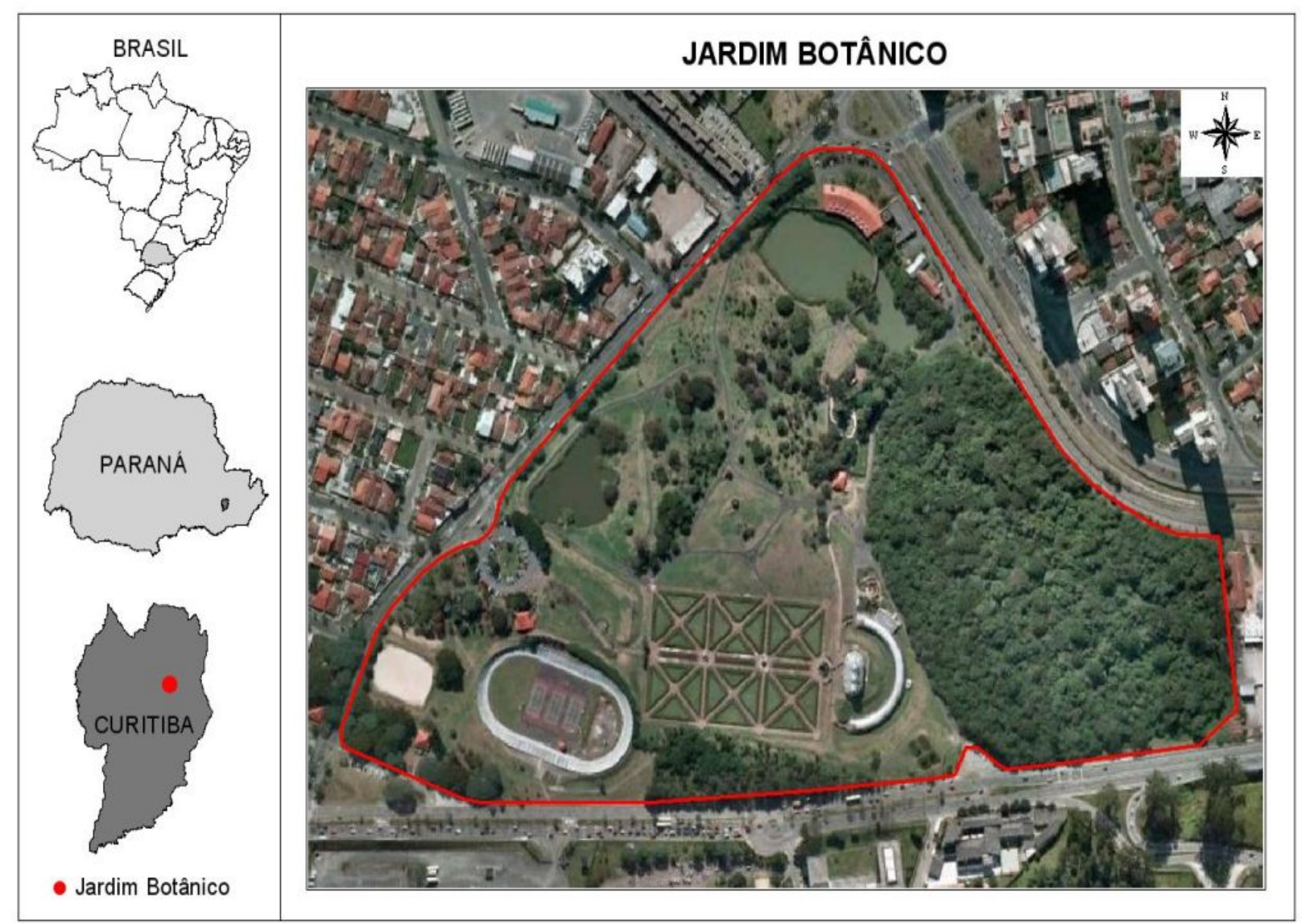

FONTE: Google Earth (2009).

No ano de 2009, segundo dados do Instituto Municipal de Turismo de Curitiba, o atrativo manteve-se em primeiro lugar entre os atrativos mais visitados pelos entrevistados (CURITIBA, 2009). Desde então não houve atualizações destes dados.

\section{PROCEDIMENTOS METODOLÓGICOS}

Com o intuito de analisar a preferência paisagística do usuário do Jardim Botânico de Curitiba, esta pesquisa tomou como base o método psicofísico, o qual foi utilizado em estudos anteriores por Kischlat (2004).

Os dez cartões postais existentes com a temática referente ao Jardim Botânico de Curitiba
(FIGURA 2) foram analisados de acordo com a tipologia e os componentes paisagísticos neles existentes a partir dos seguintes procedimentos:

a) Divisão em quadriculas 0,4 X 0,4 cm;

b) Definição da tipologia de paisagem presente nos dez cartões postais;

c) Definição dos elementos a serem analisados: divisão entre componentes naturais, antrópicos e culturais;

d) Quantificação da quantidade de quadrículas com os elementos definidos;

e) Quantificação da porcentagem destes elementos em cada paisagem.

f) Seleção dos cartões postais a serem avaliados pelos usuários. 
Figura 2 - Cartões postais Jardim Botânico de Curitiba.

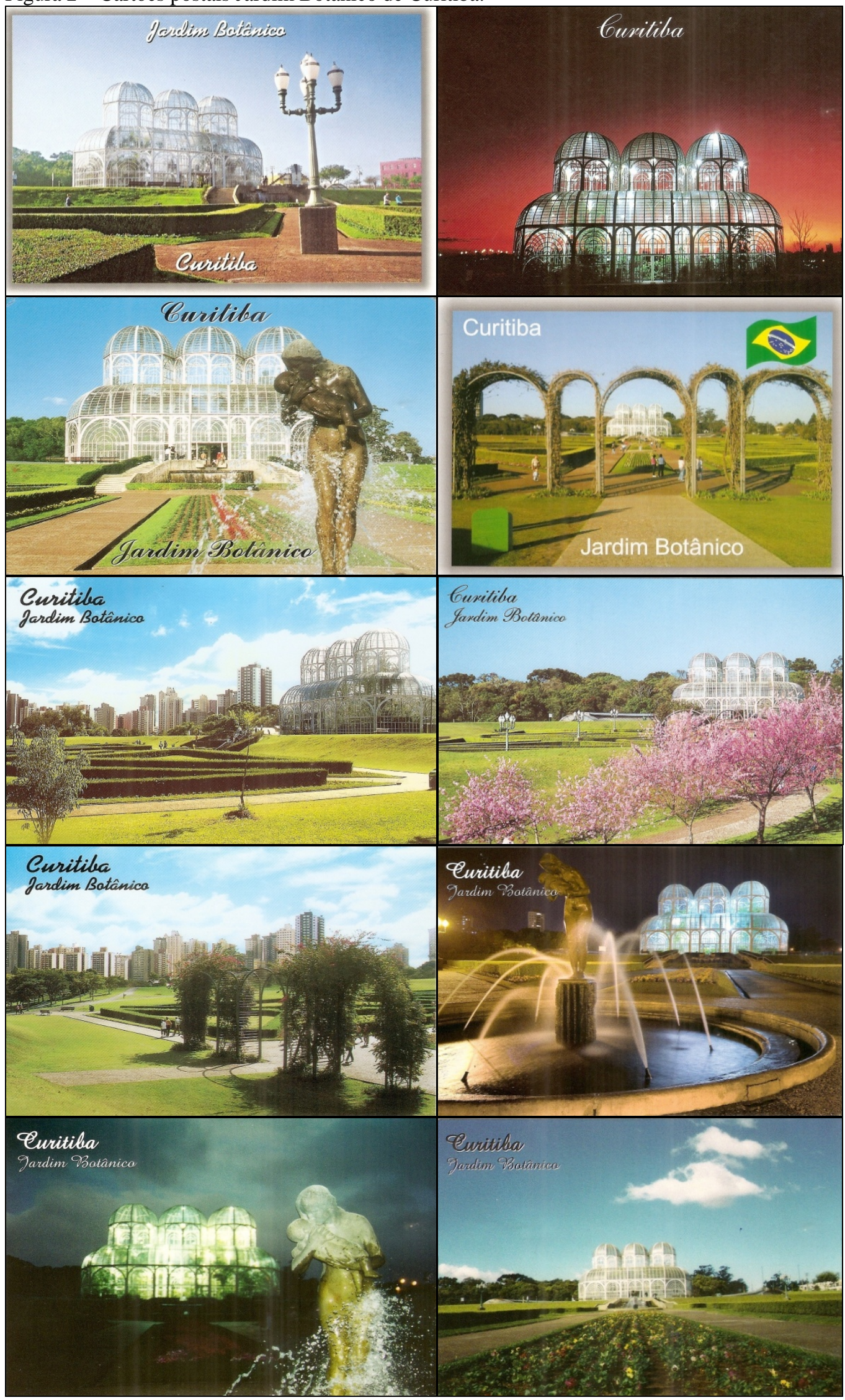

FONTE: Curitiba(2011).

AVALIAÇÃO DA PREFERÊNCIA PAISAGÍSTICA NO JARDIM...

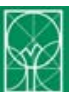


De acordo com os critérios estabelecidos por Biondi (1990) os dez cartões postais foram classificados segundo o tipo de paisagem que apresentavam e em seguida quantificados de acordo com os elementos paisagísticos neles presentes.

Foram considerados elementos paisagísticos naturais a vegetação, o céu, a água e o relevo, onde o critério vegetação foi subdividido em arbórea, gramado e ornamental. Para a análise dos elementos paisagísticos antrópicos, subdividiu-se o critério construções em estrutura física e urbanização. Os elementos paisagísticos culturais foram subdivididos nos itens monumento e pessoas.

A medida padrão dos cartões postais é de 10,5 X $15 \mathrm{~cm}$. Assim, após testes para verificar qual medida seria ideal para uma boa visualização dos elementos em análise, estabeleceu-se que cada cartão postal deveria ser dividido em 798 quadrículas de $0,4 \times \quad 0,4 \mathrm{~cm}$, conforme demonstra a figura 3.

Figura 3 - Modelo grade de quadrículas.

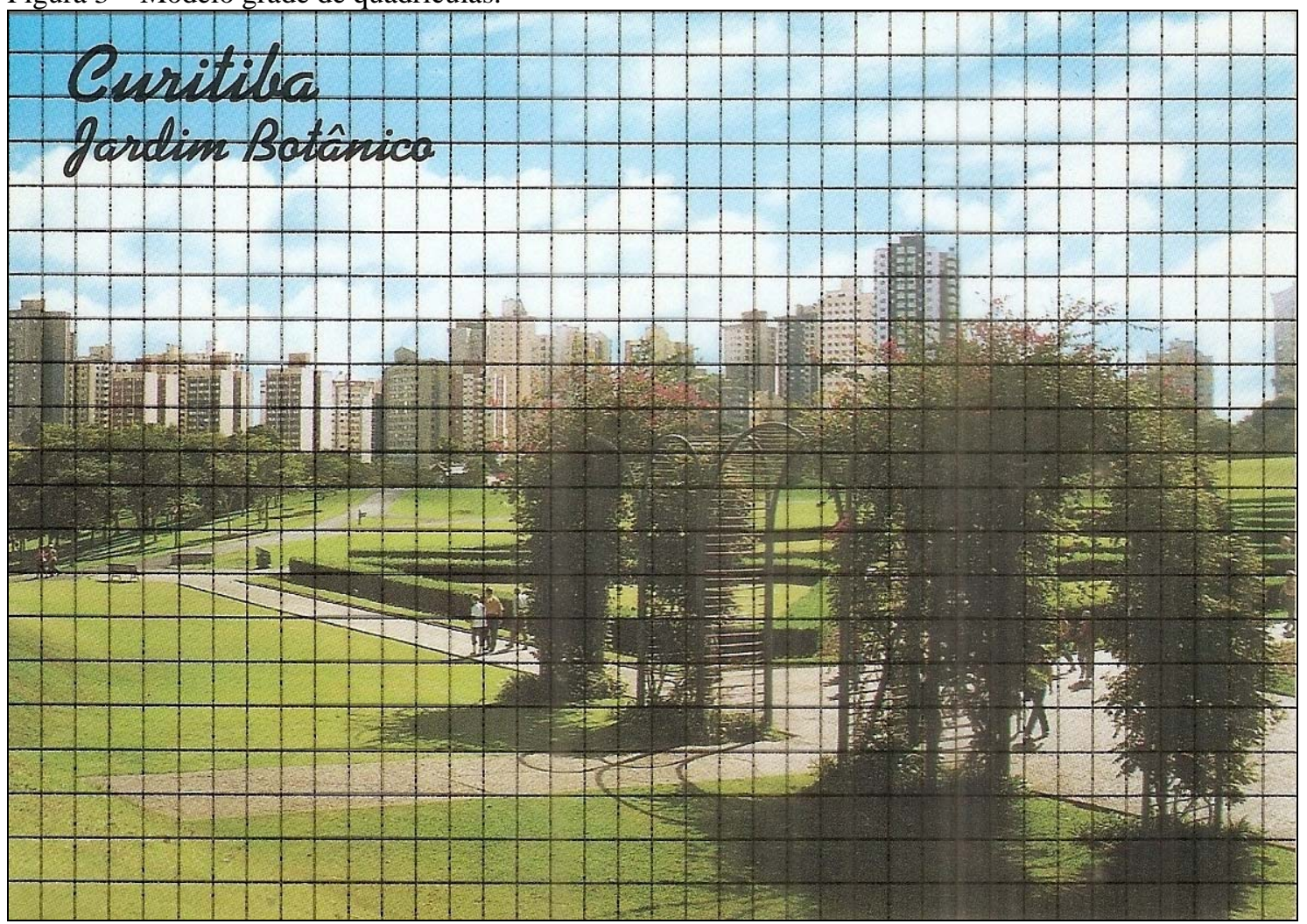

FONTE: Curitiba (2011).

Os cartões postais a serem avaliados pelos entrevistados foram selecionados de acordo com a porcentagem de elementos que apresentaram na avaliação paisagística. Assim, foram selecionados aqueles que apresentaram maior porcentagem de elementos naturais, antrópicos e culturais, totalizando três paisagens a serem avaliadas e valoradas.
No questionário de avaliação paisagística, foi solicitado aos entrevistados que indicassem sua preferência indicando uma ordem de preferência de 1 a 3.

Estes procedimentos permitiram verificar quais componentes e tipo paisagístico mais agradam ao usuário. Além de fornecer subsídios para uma discussão sobre a preferência paisagística 
de acordo com a composição e tipologia da

paisagem.

\section{RESULTADOS E DISCUSSÕES}

Após a definição da tipologia e análise dos elementos paisagísticos presentes nos dez cartões postais do Jardim Botânico de Curitiba, selecionaram-se três deles, considerando aqueles com a maior porcentagem de elementos naturais, antrópicos e culturais, para serem apresentados aos entrevistados nesta pesquisa com o intuito de conhecer suas preferências paisagísticas.

O uso de apenas três cartões postais, no momento da aplicação do questionário mostrouse eficiente nos quesito tempo e espaço, pois se tratando de um atrativo turístico tempo é de fundamental importância, já que os usuários não o querem "perder" com outras atividades que não estejam em seu roteiro, enquanto que o pequeno espaço ocupado pelos cartões postais no momento da avaliação possibilitou um fácil manuseio tanto da pesquisadora como dos entrevistados.

Assim, a tabela 1 apresenta a quantificação geral dos elementos presentes nas dez paisagens dos cartões postais analisados nesta pesquisa.

Tabela 1 - Quantificação elementos paisagísticos dos cartões postais.

\begin{tabular}{cccc}
\hline Paisagem - postal & Elemento natural & Elemento antrópico & Elemento cultural \\
\hline 1 & 82,8 & 16,7 & 0,5 \\
2 & 70,3 & 29,7 & 0 \\
3 & 89,3 & 9,8 & 0,9 \\
4 & 69,2 & 20,5 & 10,3 \\
5 & 82,3 & 17 & 0,7 \\
6 & 92,6 & 7,4 & 6 \\
7 & 83,6 & 10,4 & 0 \\
8 & 95,2 & 4,8 & 8 \\
9 & 77,5 & 14,5 & 1,1 \\
10 & 88,5 & 10,4 & 0 \\
\hline
\end{tabular}

FONTE: A autora (2011).

Observou-se que a paisagem do cartão postal 14 apresentou uma maior porcentagem de elementos antrópicos. Enquanto que a paisagem do cartão postal 43 apresentou uma maior porcentagem de elementos culturais. Por fim, a paisagem do cartão postal 89 apresentou uma maior porcentagem de elementos naturais. A figura 4 representa estes três cartões postais selecionados e utilizados na avaliação da preferência paisagística dos entrevistados. 
Figura 4 - Predominância elementos paisagísticos nos postais do Jardim Botânico de Curitiba.

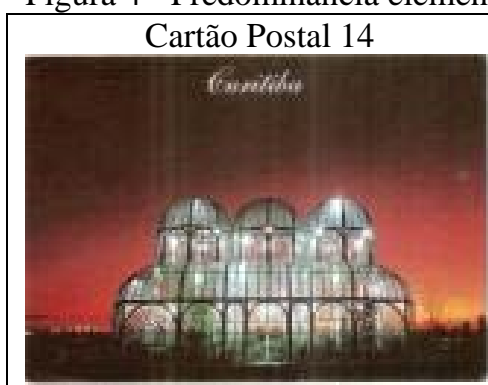

Elementos Antrópicos

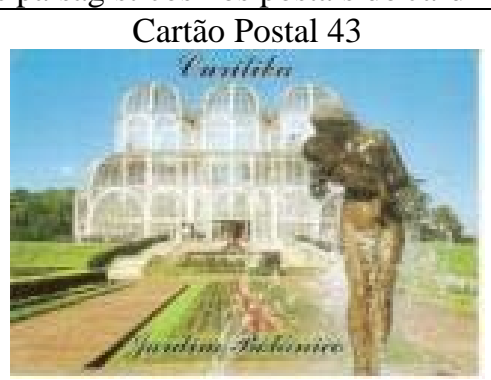

Elementos Culturais

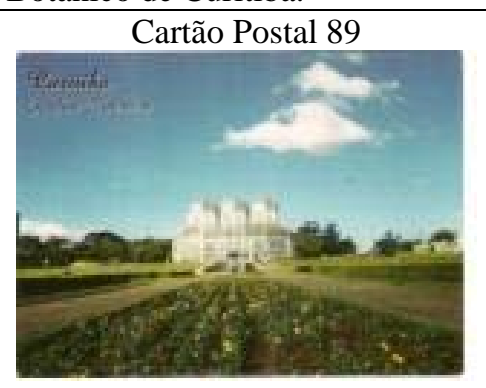

Elementos Naturais

FONTE: Curitiba (2011).

Notou-se, entretanto que as paisagens dos cartões postais 14 e 89 não possuem o elemento cultural em sua composição paisagística, assim foi verificada junto aos entrevistados a hipótese da preferência paisagística ser influenciada pela ausência ou presença de alguns dos elementos definidos para essa análise.

Na preferência paisagística geral, dentre os três cartões postais apresentados aos 985 usuários, $35 \%$ destes, elegeram os cartões postais 14 e 43 em primeiro lugar. Enquanto que $41 \%$ elegeram o cartão postal 14 em segundo lugar e 52\% elegeram o cartão postal 89 terceiro lugar.

Ao se considera o fator gênero, dentre os três cartões postais apresentados, aos 524 usuários do gênero feminino, 31\% elegeram o cartão postal $n^{\circ} 43$ em primeiro lugar. Enquanto que $43 \%$ elegeram o cartão postal n 14 em segundo lugar e $51 \%$ elegeram o cartão postal n 89 em terceiro lugar.

A preferência dos usuários do gênero feminino pelo cartão postal $n^{\circ} 43$, o qual apresenta o verde e o azul como cores dominantes na paisagem também corroboram com o resultado encontrado por Ficek e Ellis (2000), pois no ranking de preferência de cores entre indivíduos do sexo feminino estas cores figuraram em primeiro e segundo lugar respectivamente.

Na opinião dos 461 usuários do gênero masculino, o cartão postal $n^{\circ} 14$ foi eleito em primeiro lugar com $41 \%$ da preferência paisagística masculina. Enquanto que o cartão postal $n^{\circ} 43$ com $42 \%$ foi eleito em segundo lugar e o cartão postal n ${ }^{\circ} 89$ com $54 \%$ foi eleito em terceiro lugar.

A preferência dos usuários do gênero masculino pelo cartão postal $n^{\circ} 14$, o qual apresenta uma paisagem mais escura e predominância de tonalidades de vermelho, corrobora com o encontrado por Ficek e Ellis (2000) em estudo sobre a preferência de cores de acordo com o gênero, onde indivíduos do sexo masculino mostraram uma tendência em preferir o vermelho em detrimento de outras cores, enquanto que as mulheres mostraram-se menos favoráveis a sombras escuras de vermelho.

Observou-se que, os resultados encontrados confirmam a hipótese de que a preferência paisagística é influenciada pelo gênero do observador, pois segundo Tuan (1980) o fator gênero, quando comparado a outras categorias, tais como personalidade, influencia congênita e variação de humor, é uma variável segura para justificar as atitudes humanas.

Ao se considerar o fator idade, foi perceptível a diferenciação na preferência paisagística entre as diferentes faixas etárias, sendo que os grupos de usuários na faixa etária de até 18 anos e de 19-30 anos foram os únicos a posicionarem o cartão postal n 14 em primeiro lugar e o cartão postal n 89 em último lugar.

Raquel Ribeiro de Souza Silva e Daniela Biondi 
Na sequência, o grupo de usuários na faixa etária de 31-45 anos posicionou o cartão postal $\mathrm{n}^{\circ} 43$ em primeiro e segundo lugar e o cartão postal $n^{\circ} 89$ se manteve em último lugar.

No entanto, o resultado mais expressivo foi obtido nas faixas etárias de 46-60 anos e mais de 60 anos, onde o cartão postal $n^{\circ} 89$ foi posicionado em primeiro lugar e o cartão postal n 14 em último lugar.

Observou-se, ainda que, a preferência predominante, dos entrevistados da faixa etária a partir de 46 até mais de 60, pelo cartão postal $n^{\circ} 89$, o qual possui as cores frias verde e azul como dominantes na paisagem, coincide com a afirmação de Tuan (1980), de que a preferência por cores quentes diminui com o aumento da idade.

Assim, a variação de preferências, de acordo com a faixa etária, encontrados nesta pesquisa, condiz com o estudo de Zube, et al. (1983), o qual avaliou a preferência paisagística considerando a faixa etária de crianças, adultos e idosos e identificou que as correlações dos resultados entre adultos com mais de 65 anos e outros adultos apresentaram variações significativas na preferência por paisagem.

Ao se considerar o fator escolaridade, o cartão postal $n^{\circ} 14$ posicionou-se em primeiro lugar entre os usuários com ensino fundamental e graduação. Houve um empate de primeiro e segundo lugar entre os cartões postais $\mathrm{n}^{\circ} 14 \mathrm{e}$ n43 entre os usuários com pós graduação.

Apenas os usuários com ensino médio posicionaram o cartão postal $n^{\circ} 43$ em primeiro lugar, sendo que muitos dos usuários que afirmaram ter concluído o ensino médio não eram jovens e sim adultos.

Observou-se que de forma geral os resultados considerando o nível de escolaridade coincidiram com o encontrado na preferência paisagística por faixa etária, pelo fato de que os usuários de determinadas faixa etárias possuírem o mesmo nível de escolaridade.

Em relação ao cartão postal n 89, os usuários de todos os níveis de escolaridade o posicionaram em último lugar.

YU (1995) em seu estudo com grupo de chineses e ocidentais especialistas em paisagem encontrou influência do nível de escolaridade geral na preferência paisagística. Afirmou ainda que um nível geral de educação aliado a experiência com o ambiente em estudo influenciou mais a preferência dos entrevistados do que o nível de especialidade no assunto.

Nesta pesquisa a variável escolaridade também se mostrou um fator influenciável na preferência paisagística, mesmo sem considerar o nível de especialidade dos usuários em relação aos elementos considerados no estudo da paisagem.

Ao se considerar o fator origem geográfica, apenas os residentes de Curitiba posicionaram o cartão postal $n^{\circ} 14$ em primeiro lugar.

Cabe ressaltar que apesar de este cartão postal possuir como um dos aspectos negativos a ausência de representatividade, para os residentes em Curitiba esta paisagem não é estranha e dentre os demais cartões postais que retratam o Jardim Botânico foi considerada a mais atrativa.

Os usuários procedentes da região metropolitana de outros estados e de outros países posicionaram o cartão postal $\mathrm{n}^{\circ} 43$ em primeiro lugar. Este cartão postal foi o que apresentou a maior diversidade de elementos e posicionou-se em primeiro lugar na preferência paisagística geral, justificando assim a escolha pelos usuários destas três categorias.

Apenas os usuários provenientes de outras cidades do Paraná posicionaram o cartão postal $\mathrm{n}^{\circ} 89$ em primeiro lugar, enquanto que todos os 
demais usuários o posicionaram em último lugar.

Há estudos que subsidiam a afirmação de que a preferência paisagística é influenciada por fatores culturais (YANG; BROWN, 1992, YU, 1994, GOVER; GO, 2009), ressaltando que as características sociodemográficas, possuem impacto na percepção que as pessoas tem dos lugares.

Nesta pesquisa, a variável origem geográfica foi também um fator influenciável na preferência paisagística. Contudo, a ausência de estudos sobre a relação entre preferência paisagística e origem geográfica brasileira não permite discussões mais aprofundadas sobre o assunto.
As respostas às perguntas referentes às justificativas para eleger o primeiro e o último cartão postal, indicaram que a percepção paisagística geral dos entrevistados frente às imagens selecionadas para este estudo, repetiuse independente das variáveis utilizadas nesta pesquisa.

Por esta razão, optou-se pela apresentação dos resultados apontando os pontos positivos e negativos, de cada um dos três cartões postais na percepção dos usuários, conforme demonstra o quadro 1.

Quadro 1 - Percepção paisagística dos cartões postais do Jardim Botânico de Curitiba.

\begin{tabular}{|c|c|c|}
\hline $1^{\circ}$ Lugar Cartão Postal n ${ }^{\circ} 43$ & $2^{\circ}$ Lugar Cartão Postal n ${ }^{\circ} 14$ & $3^{\circ}$ Lugar Cartão Postal n 89 \\
\hline Tourilitri & Camilikh & \\
\hline Aspecto positivo & Aspecto positivo & Aspecto positivo \\
\hline $\begin{array}{l}\text { Diversidade de } \\
\text { elementos: } 49 \%\end{array}$ & $\begin{array}{l}\text { Elemento natural céu: 37\% } \\
\text { Iluminação artificial: } 48 \%\end{array}$ & $\begin{array}{l}\text { Elemento natural vegetação: } \\
35 \%\end{array}$ \\
\hline Aspecto negativo & Aspecto negativo & Aspecto negativo \\
\hline $\begin{array}{l}\text { Elemento cultural monumento: } \\
46 \%\end{array}$ & Representatividade: $15 \%$ & $\begin{array}{l}\text { Paisagem panorâmica - } \\
\text { distância: } 41 \%\end{array}$ \\
\hline Elemento Natural água: 5\% & & $\begin{array}{l}\text { Proporção elemento céu: 15\% } \\
\text { Tonalidade das cores: } 11 \%\end{array}$ \\
\hline
\end{tabular}

FONTE: Curitiba (2011).

a) Cartão Postal 14: pontos positivos e negativos

O aspecto positivo apontado por 49\% dos entrevistados em relação a este cartão postal foi a junção dos elementos cultural, natural e antrópico em um mesmo cenário, resultando, segundo Biondi e Leal (2002), em uma combinação representativa da intensidade máxima de uma paisagem, por possuir um conjunto paisagístico atrativo em sua totalidade. Neste sentido, Bastarz (2009) em seu estudo sobre preferência paisagística em Morretes, Paraná, também apontou como ponto positivo a

Raquel Ribeiro de Souza Silva e Daniela Biondi 
diversidade de componentes paisagísticos e turísticos presentes nas paisagens avaliadas.

A diversidade expressa variedade paisagística e possui maior valor do que uma paisagem homogênea, devido à presença de elementos visuais distintos e a ausência de monotonia (CANTERAS, 1992).

Com relação aos aspectos negativos, a presença do elemento água na paisagem deste cartão postal foi mencionada por 5\% dos entrevistados como algo que retirariam da paisagem, no sentido de torná-la mais atrativa.

Este resultado diverge das afirmações sobre a influência positiva da água, bem como a atratividade visual que exerce sobre os observadores de paisagens (TUAN, 1980, ZUBE, et al., 1983, YU, 1995, GONZAGA, et al., 2004, FYHRI, et al., 2009).

A quantidade inexpressiva deste elemento no cartão postal avaliado, talvez possa justificar a valoração negativa recebida por parte dos entrevistados.

Outro aspecto negativo mencionado em relação à paisagem do cartão postal $n^{\circ} 43$ foi o elemento cultural, representado pelo monumento, o qual recebe maior destaque no cenário e contrasta fortemente com os demais elementos, sendo considerado por $46 \%$ dos entrevistados um depreciador da paisagem, os quais afirmaram ainda que o retirariam da imagem, a fim de tornar o cartão postal mais atrativo visualmente.

Segundo Biondi e Leal (2002), a presença de elementos contrastantes na paisagem é responsável pelo aumento ou diminuição de sua qualidade visual. Assim, na opinião dos entrevistados a qualidade visual deste cartão postal diminuiu devido ao contraste de elementos na paisagem.

b) Cartão Postal n` 14 - pontos positivos e negativos
Os aspectos positivos apontados por 37\% dos entrevistados foi a tipologia da paisagem temporária, representada pelo pôr do sol por meio da variação das tonalidades de cores que tornam o elemento natural céu mais atrativo ao final do dia. Enquanto que $48 \%$ dos entrevistados citaram a luminosidade presente no interior da estufa do Jardim Botânico de Curitiba, como fator positivo do cartão postal $n^{\circ}$ 14.

A presença de elementos naturais é um fator de valoração positiva na paisagem destinada ao uso turístico (LEMES; NEVES, 2007). Desta forma, apesar do cartão postal $n^{\circ} 14$ possuir predominância de elementos antrópicos em sua composição paisagística, sua tipologia temporária confirma a existência de uma estreita ligação entre o turismo e a preferência por paisagens naturais.

Por outro lado, a iluminação artificial, que é um dos principais elementos de composição da arquitetura, e pode ser cênica ou de efeito de acordo com os objetivos dos projetos desenvolvidos (BRONDANI, 2006), tem importante papel na paisagem urbana, sendo que a presença de uma luminosidade artificial cênica tem como função enfatizar pontos de destaque e interesse, além de vitalizar os espaços públicos e turísticos.

Segundo Barbosa (2007), a iluminação artificial também é um fator de profunda influência nas reações humanas ao ambiente, sendo que estas reações podem variar desde a simples visão do obvio até a percepção da beleza dramática de uma paisagem iluminada. A representação noturna do Palácio de Cristal do Jardim Botânico de Curitiba no cartão postal $n^{\circ} 14$ reuniu, portanto, todas estas características.

Em relação ao aspecto negativo presente neste cartão postal, 15\% dos entrevistados, apontou a 
ausência de representatividade, pois afirmaram que apenas a imagem do Palácio de Cristal não é suficiente para identificar o atrativo turístico, Jardim Botânico de Curitiba, e demonstrar a totalidade de sua beleza paisagística.

Segundo Gândara (2008), a imagem de uma localidade turística deve corresponder à realidade, ser acreditável, ser de fácil compreensão, além de ser atrativa e capaz de despertar o desejo de visitar determinado destino. No cartão postal $n^{\circ} 14$ estes requisitos não foram totalmente contemplados, tendo em vista que a compreensão dos elementos presentes no local e dos signos do Jardim Botânico de Curitiba não são possíveis ao observador da imagem.

c) Cartão Postal n`89 - pontos positivos e negativos

A presença do elemento natural vegetação, representado pelos jardins e flores que compõem o cenário da paisagem deste cartão postal foi valorado positivamente por 33\% dos entrevistados do Jardim Botânico de Curitiba.

Este resultado coincide com estudos anteriores, os quais afirmaram ser a presença de vegetação um fator que incrementa a qualidade paisagística (GONZAGA, et al., 2004) e (CORRAZZA, 2008).

Como aspecto negativo deste cartão postal, 15\% dos entrevistados citaram a proporção do elemento natural céu na paisagem, o qual recebeu uma valoração negativa nesta pesquisa. Bobrowski et al. (2010) também encontrou uma correlação negativa entre a qualidade visual e o componente céu na paisagem, afirmando que a maior proporção deste componente afetou a heterogeneidade das paisagens utilizadas na avaliação paisagística de seu trabalho.

Entretanto, em outras pesquisas este componente não influenciou nem positiva nem negativamente os resultados quanto à preferência paisagística dos entrevistados, sendo considerado um elemento de valoração neutra na paisagem (BASTARZ, 2009) e (KISCHALAT, 2004).

Desta forma, notou-se que a preferência pelo elemento céu na paisagem é totalmente subjetiva, podendo variar de uma valoração positiva a negativa de acordo com o observador. Cabe ressaltar, portanto, que o equilíbrio entre a proporção dos elementos componentes da paisagem é essencial para elevar sua qualidade visual, e o cartão postal $n^{\circ} 89$ não atende este requisito.

Outro aspecto negativo, apontado por $11 \%$ dos entrevistados, em relação a este cartão postal foi a tonalidade de cores não atrativas, consideradas por eles como apagadas e com aspecto de imagem antiga.

Este resultado confirma as afirmações de Litton (1972), Gonzales (1981), e Canteras (1992), de que a principal propriedade visual de uma superfície é o seu colorido, sendo as principais propriedades estéticas de uma paisagem determinadas em grande parte pela combinação de suas cores. Neste sentido, Gama (2009) afirma ainda que os contrastes visuais são a combinação das cores e estas são responsáveis por conceder vida a paisagem.

A ausência de tonalidades de cores visualmente atrativas foi um dos aspectos que definitivamente corroboraram para a valoração negativa deste cartão postal.

O último aspecto negativo apontado por $41 \%$ dos entrevistados foi a tipologia panorâmica da paisagem apresentada neste cartão postal, a qual, apesar de permitir uma visualização ampla do Jardim Botânico, não foi atrativa devido à distância e o tamanho pequeno do atrativo 
principal, a estufa, ou Palácio de Cristal, demonstrado na imagem.

Este resultado difere do considerado por Griffith (1983), em seu estudo sobre os recursos visuais de um parque nacional, de que o visitante é atraído pelo alcance e a magnitude das vistas panorâmicas.

Conforme observado, este cartão postal apresentou mais aspectos negativos do que positivos, justificando assim, sua colocação geral em último lugar na preferência dos entrevistados.

Estes resultados destacam a ausência de fidelidade entre o retratado nos substitutos da paisagem, os cartões postais, e a real beleza paisagística existente no atrativo. Neste sentido, Meneses (2002) ressalta que apesar dos cartões postais serem catalisadores poderosos de marcos paisagísticos, estes marcos nem sempre correspondem a realidade.
Por outro lado, os cartões postais figuram entre os poucos produtos promocionais de uma localidade que continuam a influenciar os turistas mesmo após o retorno da viagem, pois são ferramentas utilizadas para compartilhar recordações (GOVERS; GO, 2009), e servem como uma espécie de demonstração da experiência em curso durante a viagem.

Desta forma, ao se pensar em contribuições para a gestão paisagística do Jardim Botânico de Curitiba, cabe considerar que o turismo se utiliza dos recursos do "olhar”, do "lugar” e das “imagens”, estando, estreitamente relacionado com a paisagem, por meio dos cartões postais, sendo estes importantes ferramentas de divulgação de atrativos turísticos (SOBRINHO, 2004).

\section{CONCLUSÃO}

De acordo com os resultados encontrados quanto à paisagem retratada nos cartões postais, a presença de elementos culturais na imagem do cartão postal de número 43 demonstrou-se visualmente mais agradável aos entrevistados, com a ressalva de que ao se considerar os fatores gênero, faixa etária, escolaridade e origem geográfica encontraram-se variações nesta preferência paisagística.
Assim, como subsídio para a gestão paisagística do Jardim Botânico de Curitiba está o aprimoramento das imagens de divulgação do atrativo por meio de cartões postais, devido a ausência de atratividade visual de alguns deles, conforme a opinião dos entrevistados desta pesquisa, bem como a ausência de correspondência entre a beleza real do local e a retratada nas imagens divulgadas.

\section{REFERÊNCIAS}

BASTARZ, C. Análise da preferência da paisagem do município de Morretes, Paraná como subsídio ao planejamento do turismo. $123 \mathrm{f}$. Dissertação. (Mestrado).

BIONDI, D. Paisagismo. Recife: Imprensa Universitária da UFRPE, 1990

BARBOSA, L. A. G. História e conceitos de iluminação. Pós-graduação em Projetos de Iluminação. Universidade Estácio de Sá, Rio de Janeiro, 2007. 
BIONDI, D.; LEAL, C. T. Análise da capacidade paisagística do Parque Estadual de Vila Velha, PR. In: III CONGRESSO BRASILEIRO DE UNIDADES DE CONSERVAÇÃO, 2002. Fortaleza: FBPN. p. 359-367. Anais...

BOLÓS y CAPDEVILA, M. Manual de Ciencia del Paisaje: Teoría, Métodos e Aplicaciones. Barcelona: Masson S.A., 1992.

BRONDANI, S. A. A percepção da luz artificial no interior de ambientes edificados. $153 \mathrm{f}$. Tese (Doutorado em Engenharia de Produção). Programa de Pós-Graduação em Engenharia de Produção, UFSC, Florianópolis, 2006.

CANTERAS, J. C. Introducción al paisaje. Santander: Universidad de Cantabria, 1992.

CURITIBA. Instituto Municipal de Turismo. Pesquisa de demanda turística, perfil e opinião. Curitiba, 2009.

: Jardim Botânico. Paraná - Brasil. Curitiba: Mundial Postais. cartão postal: color.

CRUZ, RITA C. A. As paisagens artificiais criadas pelo turismo. In: YÁZIGI, E. (org). Turismo e paisagem. São Paulo: Contexto, 2002, p. 107-119.

FICEK, C.; ELLIS, L. Color preferences according to gender and sexual orientation. Personality and Individual Differences, v. 31, n. 8, p. 1375 - 1379, 2001.

FYHRI, A.; JACOBSEN, J. K. S.; TØMMERVIK, H. Tourists’ landscape perceptions and preferences in a Scandinavian coastal region. Landscape and Urban Planning, v. 91, n. 4, p. 202-211, 2009.

GALVÃO, W.; SANTOS, A. C.; PIACESKI, C.; GOOD, P. L.; NUCCI, J.C. Conservação da natureza no município de Curitiba/PR. GEOUERJ. Rio de Janeiro, 2003 (CD ROM).

GAMA, L. L. M. F. Testagem de instrumentos de valoração da qualidade visual da paisagem para fins de planejamento paisagístico. In: Simpósio Nacional de Geografia Física Aplicada, 2009, Viçosa MG. Disponível em:

<http://www.geo.ufv.br/simposio/simposio/trabalhos/resumos_expandidos/eixo12/021.pdf>. Acesso em 22/12/2011.

GÂNDARA, J.M.G. A imagem dos destinos turísticos urbanos. Revista Eletrônica de Turismo Cultural. Disponível em: <http://www.eca.usp.br/turismocultural/numeroespecial.htm>. Acesso em: 18/11/2011.

GONZALEZ-BERNALDEZ, F. Ecología y Paisaje. Madrid: H. Blume Ediciones, 1981.

GONZAGA, C. A. M.; WANDEMBRUCK, A.; SEGER, C. D.; BIONDI, D. 2004. Análise paisagística da trilha recreativa do Parque Municipal do Passaúna, Curitiba, Paraná. Cad. Biodivers., v. 4, n. 2, p. 6673, 2004

GOOGLE EARTH. Mapa Jardim Botânico Municipal. Curitiba, 2009.

GRIFFITH, J. J. Análise dos recursos visuais do Parque Nacional do Caparaó. Floresta, v. 14, n. 2, p. 1521, 1983.

INSTITUTO DE PESQUISA E PLANEJAMENTO URBANO DE CURITIBA (IPPUC). Estatística Demanda Turística de Curitiba, 2007. Disponível em:

<http://www.ippuc.org.br/.../Curitiba_em_dados_Pesquisa.asp>. Acesso em: 31/05/ 2010.

KISCHLAT, E. Metodologia para Avaliação da Preferência Visual de Recursos Naturais da Paisagem para Fins Turísticos. Estudo de Caso nos Municípios de Benedito Novo e Dr. Pedrinho - 
SC. 145 f. Dissertação (Mestrado em Engenharia Florestal). Setor de Ciências Agrárias, UFPR, Curitiba, 2004.

LEMES, F. B.M; NEVES, S. C. Dos ecos do turismo aos ecos da paisagem: analises das tendências do ecoturismo e a percepção de suas paisagens. Pasos, Revista de Turismo y Patrimônio Cultural, v. 5, n. 2, p. 209-223, 2007.

LITTON Jr., R. B. Aesthetic Dimensions of Landscape. In: KRUTILLA, J. V. Natural Enviroments: studies in Theoretical and Applied analysis. Baltimore: Johns Hopkins, 1972, p. 263-291.

MENESES, U. T. B. A paisagem como fato cultural. In: YÁZIGI, E. (org). Turismo e paisagem. São Paulo: Contexto, 2002, p. 29-64.

REDE BRASILEIRA DE JARDINS BOTÂNICOS (RBJB). Jardim Botânico Municipal FMGR. Diversidade biológica nos jardins botânicos brasileiros. Rio de Janeiro, 2004.

SILVA, M. G. L. Cidades Turísticas: Identidades e Cenários de Lazer. São Paulo: Aleph, 2004 (Série Turismo).

SOBRINHO, F. L. A. Lugares, olhares e imagens: uma breve discussão sobre planejamento turístico. Múltipla, v. 10, n.16, p. $71-91,2004$.

TUAN, Y. F. (trad. Lívia de Oliveira). Topofilia: um estudo da percepção, atitudes e valores do meio ambiente. São Paulo: Difel, 1980.

YANG, B-E; BROWN, T. J. A cross-cultural comparison of preferences for landscape styles and landscape elements. Environment and Behavior, v. 24, n. 4, p. 471-507, 1992.

YU, K. Cultural variations in landscape preference: comparisons among Chinese sub-groups and Western design experts. Landscape and Urban Planning, v. 32, n. 2, p.107-126, 1995.

ZUBE, L. H.; PITT, D. G.; EVANS, G. W. A lifespan developmental study of landscape assessment. Jornal of Environment Psychology, v. 3, n. 2, p. 115-128, 1983. 